\title{
Respiratory cancers and chemical exposures in the wood industry: a nested case-control study
}

\author{
T P KAUPPINEN,${ }^{1}$ T J PARTANEN,$^{1}$ M M NURMINEN, ${ }^{1} \mathrm{~J} \mathrm{I} \mathrm{NICKELS,}^{1}$ \\ S G HERNBERG, ${ }^{1}$ T R HAKULINEN, ${ }^{2}$ E I PUKKALA, ${ }^{2}$ AND ET SAVONEN ${ }^{1}$
}

From the Institute of Occupational Health, ${ }^{1}$ and the Finnish Cancer Registry, ${ }^{2}$ Helsinki, Finland

\begin{abstract}
A cohort of 3805 men who had worked for at least one year in the particleboard, plywood, sawmill, or formaldehyde glue industries between 1944 and 1965 was followed up until 1981 . From within the cohort the 57 patients with verified "respiratory" cancer (ICD 7 codes: 160-162.1, $141,143-8)$ were defined as "cases," and 171 men without respiratory cancer from within the cohort were matched on birth year and used as controls. The comparison of exposures was carried out according to work histories and job exposure matrices for each plant. The odds ratio for exposure to wood dust was 1.03 (32 exposed cases) without provision for any latent period, and 0.97 (27 exposed cases) when provision for a minimum latent period of ten years was applied. The odds ratios were 1.60 and 1.68 , respectively, when smoking was controlled by stratification. These results did not differ significantly from unity. The estimated average level of exposure to wood dust among the exposed was $1-2 \mathrm{mg} / \mathrm{m}^{3}$ and the mean duration of exposure about ten years. Significantly (one sided test, $5 \%$ level) raised odds ratios were observed for exposure to pesticides and phenol. No single pesticide could be identified as "causative" because of frequent multiple exposures. The raised odds ratios for phenol were partly explained by smoking and exposure to pesticides which confounded the observed associations for phenol exposure. Exposure to terpenes and other heating products of coniferous woods was significantly associated with a risk of respiratory cancer when the duration of exposure exceeded five years.
\end{abstract}

Suspected or known carcinogens that have been present in the Finnish wood industry since before 1970 include wood dust, chlorophenols, formaldehyde, lindane, aldrin, heptachlor, inorganic arsenic, and certain chromates. ${ }^{1-4}$ Exhaust gases of forklift trucks have also been present in the plants since the late 1950s. Exposure to the potent carcinogen bis-chloromethyl ether (BCME) may have occurred. The thermal degradation products of glues and volatile components of coniferous woods have also been present in the air, but little is known of the possible carcinogenicity of these compounds.

Epidemiological studies of possible cancer risks in plywood and particleboard plants are few. A mortality study from the state of Washington showed statistically significant increases in mortality from cancer of the stomach and from leukaemias among plywood workers. The observed number of stomach cancers was 32 (20.9 expected) and that of leukaemias 23 (11.9 expected). The author concluded that inhaled or in-

Accepted 17 June 1985 gested wood dust or breakdown products of wood could have caused these excesses. ${ }^{5}$ A Swedish register based study showed a significant increase only in the incidence of breast cancer among female plywood and fibreboard workers (11 observed, 3.9 expected), but it is difficult to connect this finding with any chemical exposure. No excess of respiratory cancer was observed and no nasal cancers were found, the expected value being $1 \cdot 1{ }^{6}$

The possible cancer risks in sawmills are insufficiently explored. The International Agency for Research on Cancer (IARC) stated in 1982 that the data are insufficient for an assessment of the carcinogenic risks in the lumber and sawmill industries. ${ }^{7}$ Some Swedish studies have suggested an association between exposure to chlorophenols and soft tissue sarcomas, ${ }^{89}$ malignant lymphomas, ${ }^{10}$ and cancer of the nose and nasopharynx. ${ }^{11}$ These associations could not be confirmed in the Washington study where the observed and expected values of soft tissue sarcomas and malignant lymphomas among sawmill workers did not differ significantly. No definite information, however, about the possible exposure to 
chlorophenols was given in that study. ${ }^{12}$ In the Swedish study workers in sawmills and planing mills had a slight excess of Hodgkin's disease ( 25 cases observed, 20.3 expected) and of cancer of the lip (37v 24.8). There was no excess of nasal cancers $(6 v 6.3)$ nor of cancer of the lower respiratory organs (125v $158 \cdot 3){ }^{6}$

The present study deals with possible associations between cancers related to the respiratory tract and the main chemical exposures in the particlewood, plywood, sawmill, and formaldehyde glue industries. There was no association with exposure to formaldehyde. ${ }^{13}$ Some other associations, however, were found and we report these data.

\section{Material and methods}

\section{DESIGN}

The cohort based case-control design was adopted. Both the cases and the controls were selected from a cohort base of an average 25 year retrospective follow up of male production workers in the particleboard, plywood, sawmill, and formaldehyde glue industries. The plants were selected according to the availability of retrospective personnel registers since 1944. The cohort was formed of $\mathbf{3 8 0 5}$ male workers born after 1904 who had entered these industries at any time between 1944 and 1965. The numbers of particleboard, plywood, sawmill, and glue production workers in the cohort were 619, 1780, 1394 and 12. The range of birth year was 1905-50. A minimum of one year of employment in at least one of the 19 plants under study was required.

From the cohort, 151 primary malignant tumours were notified as new incident cancers to the Finnish Cancer Registry between January 1957 and December 1980 inclusive. The case coverage of the Finnish Cancer Registry is judged to have been complete during that period. ${ }^{14}$ Cancers originating in organs being in direct contact with chemical agents during respiratory exposure were of primary interest. These cancers were labelled "respiratory" for short and refer in this study to 60 malignant tumours of the following primary sites (ICD 7 codes): tongue (141) one, mouth, other (143-144) nil, pharynx (145-148) one, nose, sinuses (160) nil, larynx, epiglottis (161) four, and lung, trachea (162.0-1) 54 .

A request for histological or cytological specimens was addressed to the respective hospitals and laboratories, and in 49 cases specimens were available. These were re-evaluated by the pathologist of our team (JN). Necropsy and hospital protocols were studied for the 11 cases lacking histological or cytological samples. Two cases were rejected due to a false preliminary diagnosis of cancer and one as having chronic lymphocytic leukaemia. The final size of the group of cases was thus 57.

Three control subjects for each case (171 men in all) were selected from within the cohort and they were individually matched to each case by birth year. Each control subject had to be alive and free from respiratory cancer at the date of diagnosis of the corresponding case. The selection of the controls was random within these constraints. The exposure histories were assessed for each control until the month of diagnosis of his matched case.

\section{EVALUATION OF EXPOSURES}

The job exposure matrix (JEM) approach was used to determine exposures. An occupational hygienist (TK) constructed plant specific JEMs for all 12 prevalent exposing agents and for every calendar year of the follow up period. The hygienic data of the plant, general hygienic data on exposures, and information on ventilation, work procedures, and other relevant factors at the plants were used in the construction of JEMs. Each plant was visited, and supervisors or workers with long experience were interviewed. In two plywood plants, one particleboard plant, and in one sawmill, measurements were made of some air contaminants for which earlier quantitative data were lacking. The JEMs were constructed systematically on the basis of preset exposure criteria and without any knowledge of the case-control status of the individual workers.

The work histories of the cases and controls were assessed independently of the construction of JEMs and by a different person (ES) for the purpose of minimising information bias in the evaluation of exposure. Work histories were based as much as possible on plant registers which were considered to give equally accurate information of jobs for the cases and controls. Because the job descriptions were sometimes inaccurate or lacking in the plant registers, however, plant personnel were used as an additional source of information to specify or confirm the work history of the subjects. Neither the case-control status nor the exact hypothesis of the study were conveyed to those interviewed. Postal questionnaire responses of the cases, controls, or their relatives also included information on the jobs, but they were used only to check if the work history included other jobs with probable exposure to the studied chemical agents, and to obtain data on smoking. The jobs of the subjects obtained with the procedure mentioned were coded into the occupational categories used in the JEMs. The JEMs included in all 73 occupational categories which were internally homogeneous regarding the exposures.

The linking of work history data and JEMs was carried out by means of a computer program that calculated several exposure indices for every case and 
control. The basic indicators of wood dust exposure were the estimated mean level $\left(\mathrm{mg} / \mathrm{m}^{3}\right)$ and cumulative dose (product of level and exposure time, summed over all exposure periods; $\mathrm{mg} / \mathrm{m}^{3}$-years). At least one month of exposure time to wood dust was required for the inclusion of a person into the "exposed" category. The hygienic data on wood dust enabled three exposure levels to be classified: low $\left(0 \cdot 1-1 \mathrm{mg} / \mathrm{m}^{3}\right)$, moderate $\left(1-5 \mathrm{mg} / \mathrm{m}^{3}\right)$, and high (over $5 \mathrm{mg} / \mathrm{m}^{3}$ ). A similar method was used in the construction of exposure indices to chlorophenols. Some of the general exposure data of exposure to wood dust and chlorophenols have been reported in more detail elsewhere. ${ }^{1516}$ Other exposures were determined qualitatively (yes/no) and as a function of exposure time.

Exposure through the skin (pesticides, chlorophenols, phenol) and inhalation exposure of dust containing chemicals were also considered. Potential exposure to bis-chloromethyl ether was considered possible in departments where urea-formaldehyde resins, which contain ammonium chloride, were used.

Smoking histories were determined by means of a postal questionnaire mailed to living cases and controls, and to close relatives of those who had died. The data were completed by a telephone interview if necessary. Information on smoking was obtained for 39 cases (68\%) and 130 controls $(76 \%)$. Questions were asked on the type of smoking (cigarettes/pipe/cigars), mean consumption of cigarettes, years of smoking, and ages when starting and ceasing smoking.

\section{STATISTICAL METHODS}

The cases and controls were tabulated according to exposure to chemicals as such and stratified according to the duration of smoking in order to control possible confounding effects. Because there were rather few non-smokers, especially among the cases, the division was made between "light" smokers and "heavy" smokers instead of smokers and nonsmokers. The division could not be made according to "dose" (pack-years) because the question concerning the amount of smoking was rather incompletely answered. Data on years of smoking were more complete and therefore "heavy" smokers were defined as those having smoked for over 35 years.

The odds ratio estimates ( $O R$ ) were calculated by the maximum likelihood method derived by Gart, ${ }^{17}$ with confidence limits using Cornfield's procedure. ${ }^{18}$ The significance level adopted was one sided alfa = 0.05 , corresponding to the calculated $90 \%$ confidence limits of the ORs.

The data also allowed the stratification of exposure to wood dust and chlorophenols according to the esti- mated level and dose of exposure. Other chemical agents could be stratified according to the duration of exposure. Mantel's extension of the Mantel-Haenszel test was applied in the assessment of the exposureresponse relations. ${ }^{19}$ The categories of exposure were scored using the medians of exposure time (in years) in the trend analyses.

Although the work history information was collected mainly from plant registers and with similar methods for every subject, there was evidence of different degrees of completeness in work histories between living and dead subjects. More detailed information was obtained from living subjects as measured by the number of jobs mentioned during a similar follow up period. Because there were considerably more living people among the controls $(67 \%)$ than among the cases $(5 \%)$, the data were stratified by survival status to achieve a roughly symmetrical level of accuracy in the work history information.

Matching was dismissed in the analyses because stratified tabular analyses could not be done with matching retained. Conditional multiple logistic analysis was attempted but difficulties in interpretation arose, mainly because of relatively high correlations in the data between some independent variables.

In some analyses provision for "latent" period 8 was attempted by excluding exposures during the $1 \mathbb{P}$ years immediately preceding the diagnosis of the cases. For the controls, correspondingly, exposures? during the 10 years before the diagnoses of the respective cases were excluded in these analyses.

\section{Results}

Table 1 shows the ORs for different exposures stratified according to survival status and years of smoking. Some of the observed ORs for exposure to pesticides, phenol, and exhaust gases were statistically significant at the $5 \%$ level (one sided). In particular, ORs of exposure to pesticides in wood dust with provision for a latent period of 10 years were high, 13.1 and 11.8 without and with adjustment for years of smoking. No confounding by birth year was present (correlation coefficients between birth year and exposure indicators varied between -0.11 and 0.04 in the controls).

Table 2 shows in more detail the exposure of the cases to pesticides. It was not possible to identify the possible causative chemical agents due to multiple exposures and the rather small number of exposed cases. The most common commercial chemicals used were Tancas C (produced in Great Britain) and Antimögel and Basileum SPI (produced in Federal Republic of Germany).

Table 3 shows the results of the trend analysis of 
Table 1 Odds ratio estimates ( $\hat{R}$ ) for respiratory cancers and the exposures with provision for minimum 10 year latent period and without latent period. Adjusted for survival status

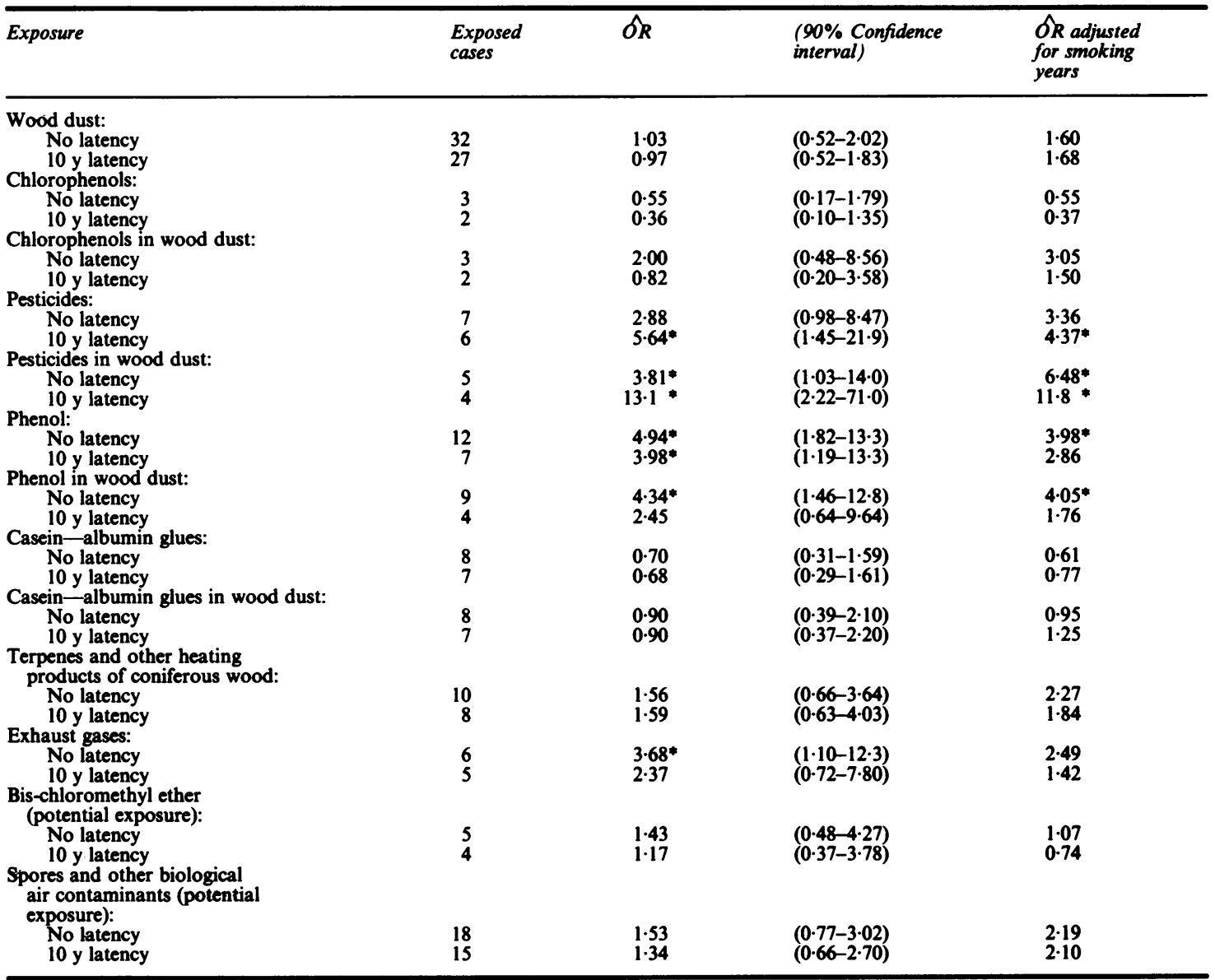

"Statistically significant at the $5 \%$ level (one sided).

possible exposure-response relations. A statistically significant exposure-response relation was observed for the duration of exposure to pesticides $\left(\chi^{2}=7.07\right.$, $\mathrm{p}=0.008)$, pesticides in wood dust $\left(\chi^{2}=10.53, \mathrm{p}=\right.$ $0.001)$, and terpene compounds $\left(\chi^{2}=4.40, \mathrm{p}=\right.$ 0.036).

None of the ORs for wood dust and chlorophenols was statistically significant. The estimated mean level of exposure to wood dust was about $1.0 \mathrm{mg} / \mathrm{m}^{3}$ among the exposed cases and about $1.5 \mathrm{mg} / \mathrm{m}^{3}$ among the exposed controls when calculated according to the work histories in the plants and the respective job exposure matrices. The mean duration of exposure was nine years for the exposed cases and 11 years for the exposed controls. The estimated mean level of exposure to chlorophenols was about $0.2 \mu \mathrm{mol} / 1$ among the exposed cases and about $1.7 \mu \mathrm{mol} / 1$ among the exposed controls as evaluated on the basis of the concentrations of chlorophenols in urine of exposed workers in different sawmill occupations. ${ }^{16}$

A slight concentration of cases in certain jobs was observed when the occupations of the cases and controls were compared. Such jobs in sawmills were, for example, sorting in timber yard (4 cases, 6 controls), sawing and edging ( 7 cases, 9 controls), other occupations (6 cases, 13 controls) and unknown occupations ( 6 cases, 4 controls). In plywood plants, a concentration was observed in handling of logs (7 cases, 11 controls), peeling department (10 cases, 13 controls), other jobs in the finishing department (10 cases, 14 controls), and manufacture of blockboard ( 2 cases, 2 controls). From the point of view of exposures there is little in common between these occupations. One common factor in some of these 
Table 2 Exposure to pesticides among the cases

\begin{tabular}{|c|c|c|}
\hline Job of the case & $\begin{array}{l}\text { Period of } \\
\text { exposure }\end{array}$ & Pesticides \\
\hline Finishing of plywood* & $1959-81$ & $\begin{array}{l}\text { Chlorophenols, lindane, aldrin, } \\
\text { parathion, tributyltin oxide }\end{array}$ \\
\hline $\begin{array}{l}\text { Hot pressing and finishing } \\
\text { of plywood* }\end{array}$ & $1959-64$ & $\begin{array}{l}\text { Chlorophenols, lindane, aldrin, } \\
\text { tributyltin oxide }\end{array}$ \\
\hline Finishing of plywood* & $1968-74$ & $\begin{array}{l}\text { Arsenic pentoxide, chromates, copper } \\
\text { sulphate, chlorophenols, lindane, } \\
\text { aldrin, tributyltin oxide }\end{array}$ \\
\hline Hot pressing of plywood & $1967-71$ & $\begin{array}{l}\text { Arsenic pentoxide, chromates, copper } \\
\text { sulphate, parathion, chlorophenols, } \\
\text { lindane, aldrin, tributyltin oxide }\end{array}$ \\
\hline Finishing of plywood* & $1968-71$ & $\begin{array}{l}\text { Arsenic pentoxide, chromates, copper } \\
\text { sulphate, parathion, chlorophenols, } \\
\text { lindane, aldrin, tributyltin oxide }\end{array}$ \\
\hline Finishing of plywood* & $1967-70$ & $\begin{array}{l}\text { Arsenic pentoxide, chromates, copper } \\
\text { sulphate, parathion, chlorophenols, } \\
\text { lindane, aldrin, tributyltin oxide }\end{array}$ \\
\hline Hot pressing of plywood & $1964-68$ & $\begin{array}{l}\text { Arsenic pentoxide, chromates, copper } \\
\text { sulphate }\end{array}$ \\
\hline
\end{tabular}

* Exposed also to pesticides attached to wood dust.

Table 3 Odds ratio estimates ( $\hat{R}$ ) for respiratory cancers and some quantitative exposure indicators without provision for minimum latent period. Adjusted for survival status

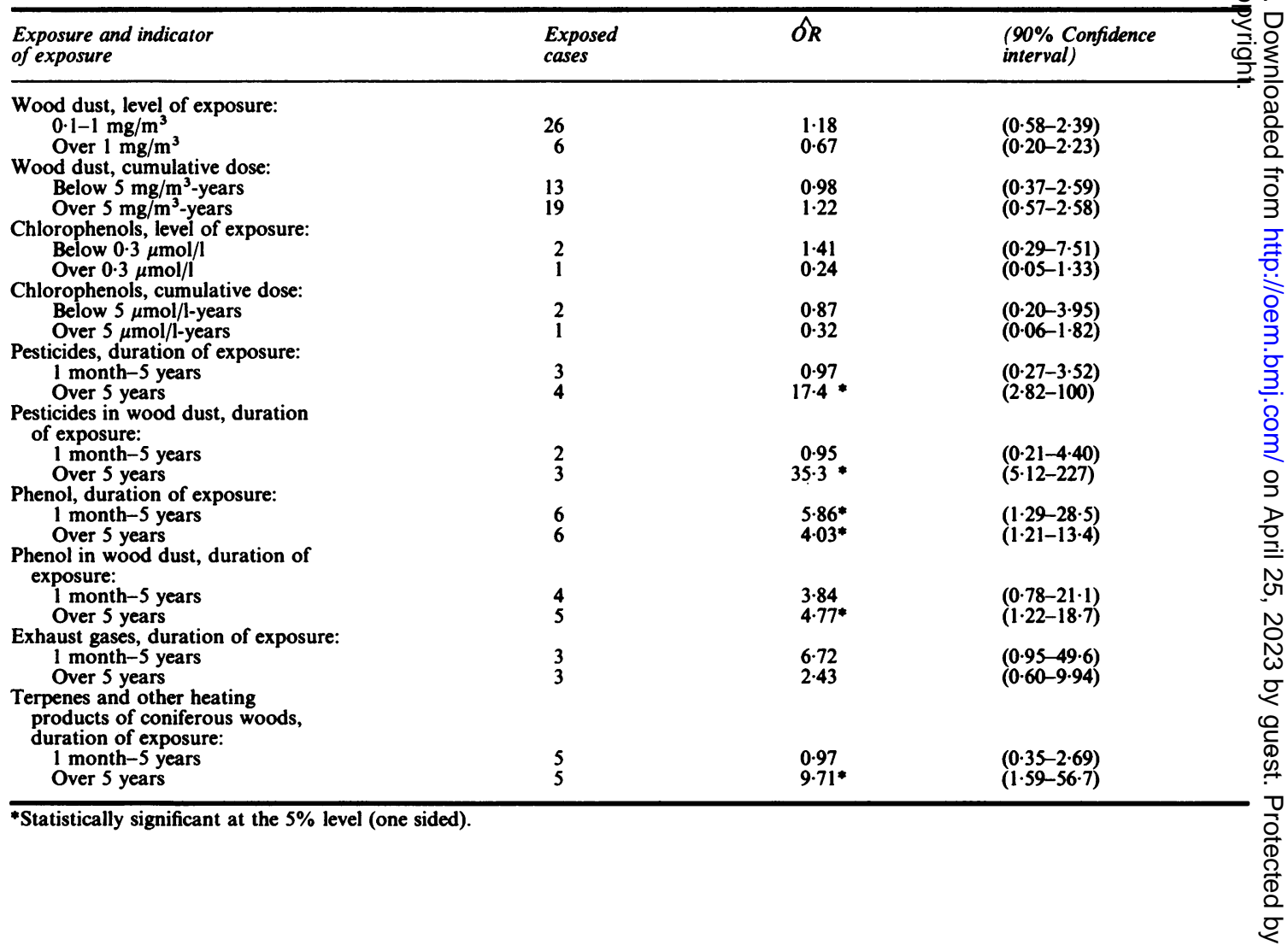


occupations can be found, however: for sawing and edging and peeling department heavy exposure to terpenes and other heating products of coniferous woods is common.

\section{Discussion}

It is well established that hardwood dust causes nasal adenocarcinoma. ${ }^{7}$ In a Scandinavian study an association was also found between nasal and sinus paranasal cancer and exposure to softwoods (mainly pine and spruce, but birch was also included) ${ }^{20}$ Rang and Acheson observed a correlation between the dustiness of work and the incidence of bronchial cancer among furniture workers in England, ${ }^{21}$ but this correlation disappeared when the same cohort was followed up further. ${ }^{22}$ The present study did not show any associations between exposure to wood dust and respiratory cancers.

Some Swedish studies have shown a connection between exposure to chlorophenols and soft tissue sarcomas and malignant lymphomas. ${ }^{8-10}$ An association with nasal and nasopharyngeal cancers has also been suggested. ${ }^{11}$ No reliable information of a possible connection between exposure to chlorophenols and cancers of the lower respiratory tract has been published to our knowledge. The present study did not show any indications of such an association. Because the number of exposed cases was small, however, the statistical power of this study is weak, and a low risk cannot be excluded. Another reason for cautious interpretation is that only sawmill workers were coded as exposed to chlorophenols because their exposure is rather well defined and they are not exposed to other pesticides. Some plywood workers, however, may also have been exposed to a mixture of pesticides including chlorophenols (see table 2).

Significantly increased ORs were observed for exposure to pesticides used in plywood plants when a latent period of ten years was applied. This result could not be explained by smoking. An exposureresponse relation was observed for pesticides as such and as attached to wood dust. The pesticides used in the 1960s in manufacturing plywood include known or suspected carcinogens such as inorganic arsenic, chromates, chlorophenols, aldrin, and lindane. It seems reasonable to conclude that the observed excess was probably caused by occupational exposure to pesticides.

Significantly increased but inconsistent ORs were observed for exposure to phenol. For these, chance or some factor other than exposure to phenol is possibly responsible, as provision for a latent period of ten years resulted in lower values of $O R$, and the duration of exposure had no effect. Phenol and other phenolic compounds may exert a promotor activity ${ }^{23}$; this may be of practical importance if exposure to initiators occurs. Exposure to possible initiators such as certain pesticides and formaldehyde is quite common in plywood plants. The ORs of phenol are also confounded by exposure to pesticides. When the workers exposed to both phenol and pesticides were excluded, the observed OR decreased from 4.9 (significant) to 2.6 (not significant).

There is evidence that exhaust gases contain a wide range of carcinogens such as polycyclic aromatic hydrocarbons and related compounds. ${ }^{24}$ In this study only one OR for exposure to exhaust gases of forklift trucks was significantly raised. The slightly increased ORs were partly explained by smoking differences. They were not dose related as measured by the duration of exposure and they decreased when a latent period of ten years was used.

The ORs for terpenes and other heating products of coniferous woods were non-significantly increased but significantly correlated with the duration of exposure. This could not be explained by differences in smoking habits. In addition, there was a concentration of cases to jobs with heavy exposure. Typical air contaminants in these jobs are sawing vapours in sawmills or drying fumes in plywood plants. The sawing vapours are known to consist mainly of monoterpenes such as $\alpha$-pinene, $\beta$-pinene, and $\Delta$-carene. ${ }^{25}$ Terpenes can react with atmospheric ozone to form allergenic and unstable hydroperoxide compounds. ${ }^{26}$ The drying fumes of coniferous veneers contain not only monoterpenes but also a complex mixture of other compounds - for example, derivatives of abietic, pimaric, and other resin acids of wood. ${ }^{27}$ The possible risk of cancer associated with volatile components of coniferous woods is still unknown and requires further study.

Much effort was devoted to the avoidance of biases, especially information bias in the determination of exposures (see "Evaluation of exposures"). The work histories of those who had died, however, were somewhat less complete than for those living. Because matching by survival status was not made, less complete information on the jobs, and consequently on exposures, was obtained for the cases (mostly dead) than for the controls (mostly alive). The bias was corrected by adjusting the ORs by survival status.

The effect of misclassification of exposures is probably small due to the detailed and checked JEMs used. Although the entire work histories were collected by a mailed questionnaire, the jobs held outside the plants studied were not used in the analysis of data because it would have been too laborious to check all the possible exposures from the numerous previous employers. This omission of part of the work histories may be a source of misclassification of exposures. This is probably not the case in the present 
study, however, because additional (omitted) exposures to the chemical agents studied seemed to be infrequent and rather evenly distributed among the cases and controls. In sum, the dose estimates used in exposure-response calculations may in some cases (wood dust, for example) be symmetrically underestimated.

The most important potential confounding factor in this study was probably smoking. Nevertheless, the ORs changed little when the data were stratified according to the duration of smoking. In the analysis of the data possible confounding by other occupational exposures was not checked with precision. The stratification by other confounders apart from smoking was omitted because of insufficient data.

The follow up of the studied population was perhaps not long enough, about 25 years on average. Should some carcinogen have a long latent time, its effect cannot be shown. Also the number of exposed cases was rather small in many tabulations. The study will therefore be continued as a prospective follow up.

We acknowledge the help provided in various phases of the study by the plants and employees concerned; the steering group of the study; hospitals and laboratories that kindly provided us with tissue specimens; Professor O Axelson of the University of Linköping, Sweden; Dr Kurppa and Ms Leena Lodenius, Institute of Occupational Health, Helsinki; Mr K J Thiel, (presently with Blanz \& Co); Professor H Vainio, International Agency for Research on Cancer; and the staff of the MRC Environmental Epidemiology Unit, Southampton, UK. Ms R Luukkonen, Institute of Occupational Health in Helsinki, programmed the job exposure matrices. Financial assistance has been granted by the Finnish Work Environment Fund.

\section{References}

${ }^{1}$ IARC monographs on the evaluation of the carcinogenic risk of chemicals to humans. Suppl 4. Chemicals, industrial processes and industries associated with cancer in humans. Lyon: International Agency for Research on Cancer, 1982.

${ }^{2}$ IARC monographs on the evaluation of the carcinogenic risk of chemicals to humans. Vol 20. Some halogenated hydrocarbons. Lyon: International Agency for Research on Cancer, 1979.

${ }^{3}$ Albert RE, Sellakumar AR, Laskin S, Kuschner M, Nelson N, Snyder CA. Gaseous formaldehyde and hydrogen chloride induction of nasal cancer in the rat. JNCI 1982;68:597-603.

${ }^{4}$ Kerns WD, Pavkov KL, Donofrio DJ, Gralla EJ, Swenberg JA. Carcinogenicity of formaldehyde in rats and mice after longterm inhalation exposure. Cancer Res 1983;43:4382-92.

${ }^{5}$ Milham S. Neoplasia in the wood and pulp industry. Ann NY Acad Sci 1976;271:294-300.

${ }^{6}$ Malker H, Weiner J. The cancer-environment registry 1961-1973. Examples of the use of register epidemiology in studies of the work environment. Arbete och Hälsa 1984:9. Stockholm: Arbetarskyddsverket, 1984. (In Swedish.)

${ }^{7}$ IARC monographs on the evaluation of the carcinogenic risk of chemicals to humans. Vol 25. Wood, leather and some associated industries. Lyon: International Agency for Research on Cancer, 1981.

${ }^{8}$ Hardell L, Sandström A. Case-control study: soft-tissue sarcomas and exposure to phenoxyacetic acids or chlorophenols. $\mathrm{Br} J$ Cancer 1979;39:711-7.

${ }^{9}$ Eriksson M, Hardell L, Berg NO, Möller T, Axelson O. Soft-tissue sarcomas and exposure to chemical substances: a case-referent study. Br J Ind Med 1981;38:27-33.

${ }^{10}$ Hardell L, Eriksson M, Lenner P, Lundgren E. Malignant lymphoma and exposure to chemicals, especially organic solvents, chlorophenols and phenoxy acids: a case-control study. $\mathrm{Br} J$ Cancer 1981;43:169-76.

${ }^{11}$ Hardell L, Johansson B, Axelson O. Epidemiological study of nasal and nasopharyngeal cancer and their relation to phenoxy acid or chlorophenol exposure. Am J Ind Med 1982;3:247-57.

12 Milham S. Herbicides, occupation, and cancer. Lancet 1982;ii:1464-5.

${ }^{13}$ Partanen T, Kauppinen T, Nurminen M, et al. Formaldehyde exposure and respiratory cancers: a case-referent study among Finnish woodworkers. Scand J Work Environ Health (in press).

${ }^{14}$ Saxén E, Teppo L. Finnish cancer registry 1952-1977. Twenty-five years of a nationwide cancer registry. Helsinki: Finnish Cancer Registry, 1978.

${ }^{15}$ Kauppinen T, Lindroos L, Mäkinen R. Concentrations of wood dust measured in the workroom air at sawmills and plywood factories. Staub-Reinhalt Luft 1984;44:322-4. (In German.)

${ }^{16}$ Kauppinen T, Lindroos $\mathrm{L}$. Chlorophenol exposure in sawmills. Am Ind Hyg Assoc J 1985;46:34-8.

${ }^{17} \mathrm{Gart}$ JJ. The comparison of proportions: a review of significance tests, confidence intervals and adjustments for stratification. Rey Int Stat Inst 1971;39:148-69.

${ }^{18}$ Cornfield J. A statistical problem arising from retrospective stud ies. In: Neyman J, ed. Proceedings of the third Berkeley sym posium on mathematical statistics and probability. Vol Berkeley: University of California Press, 1956:135-48.

${ }^{19}$ Mantel N. Chi-square tests with one degree of freedom: extensions of the Mantel-Haenszel procedure. Journal of the American Statistical Association 1963;58:690-700.

${ }^{20}$ Hernberg S, Westerholm P, Schultz-Larsen K, et al. Nasal and sinonasal cancer. Connection with occupational exposures in Denmark, Finland and Sweden. Scand J Work Environ Health 1983;9:315-26.

${ }^{21}$ Rang EH, Acheson ED. Cancer in furniture workers. Int J Epidemiol 1981;10:253-61.

${ }^{22}$ Acheson ED, Pippard EC, Winter PD. The mortality of English furniture makers. Scand J Work Environ Health 1984;10:211-7.

${ }^{23}$ Boutwell RK, Bosch DK. The tumour-promoting action of phenol and related compounds for mouse skin. Cancer Res 1959;19:413-24.

${ }^{24}$ IARC monographs on the evaluation of the carcinogenic risk of chemicals to humans. Vol 32. Polynuclear aromatic compounds, Part 1. Chemical, environmental and experimental data. Lyon: International Agency for Research on Cancer, 1983.

${ }^{25}$ Levin JO. Exposure to sawing vapours-identification and quantification of terpene components. Undersökningsrapport 1978:36. Stockholm: Arbetarskyddsstyrelsen, 1978. (In Swed- N ish.)

${ }^{26}$ Lindgren B, Norin T. Chemistry of wood resin. Svensk Papperstidning 1969;72:143-53. (In Swedish.)

${ }^{27}$ Cronn DR, Truitt SG, Campbell MJ. Chemical characterization of plywood veneer dryer emissions. Atm Environ 1983;17:201-11. 